\title{
Analisis Koordinasi Sistem Proteksi Trafo Distribusi 20 KV (Studi Kasus PT. PLN PERSERO Unit Lamongan)
}

\author{
Nahdia Rupawanti BR \\ Program Studi Teknik Elektro, Fakultas Teknik, Universitas Islam Lamongan1 \\ email : nahdia@unisla.ac.id
}

\begin{abstract}
ABSTRAK
Sistem distribusi tenaga listrik yang menggunakan kabel udara atau kabel tanah sering mengalami berbagai gangguan. Gangguan yang sering terjadi adalah gangguan simetri atau gangguan tak simentri yang dapat berupa hubungan singkat satu fase ke tanah, antar fasa ataupun putusnya salah satu atau lebih. Untuk mengetahui besarnya arus gangguan tersebut diperlukan analisis sistem distribusi transformator untuk mengetahui gangguangangguan yang akan terjadi.

Transformator yang merupakan peralatan utama dalam sebuah GI harus diperhatikan untuk mendapat mengetahui rangkaian arus dan pengamanan yang tepat. Perancangan setting trafo yang tepat merupakan suatu upaya melindungi peralatan, sistem serta kebutuhan konsumen dari gangguan yang mungkin terjadi dalam sistem distribusi. Perhitungan arus gangguan dan besarnya arus nominal transformator akan digunakan sebagai acuan penting dalam penentuan setting trafo dalam penyebaran tegangan ke konsumen-konsumen.

Dari hasil perhitungan tersebut dapat disimpulkan bahwa waktu kinerja relay penyulang lebih lambat dibandingkan dengan waktu relay dalam perhitugan. Data dilapangan masih dalam kondisi yang sesuai (perbedaanya tidak terlalu jauh), sehingga keseluruhan setting OCR - GFR yang ada dilapagan masih dalam kondisi baik.
\end{abstract}

Kata kunci: Gangguan, Transformator, Setting, OCR-GFR

\section{PENDAHULUAN \\ Latar Belakang}

Sistem Tenaga Listrik terdiri dari beberapa sub sistem, yaitu Pembangkitan, Transmisi, dan Distribusi. Tenaga listrik disalurkan ke masyarakat melalui jaringan distribusi. Jaringan distribusi merupakan bagian jaringan listrik yang paling dekat dengan masyarakat. Jaringan distribusi dikelompokkan menjadi dua, yaitu jaringan distribusi primer dan jaringan distribusi sekunder.

Tegangan distribusi primer yang dipakai PLN adalah $20 \mathrm{kV}, 12 \mathrm{kV}, 6 \mathrm{kV}$. Pada saat ini, tegangan distribusi primer yang cenderung dikembangkan oleh PLN adalah $20 \mathrm{kV}$. Tegangan pada jaringan distribusi primer diturunkan oleh gardu distribusi menjadi tegangan rendah yang besarnya adalah 380/220 $\mathrm{V}$, dan disalurkan kembali melalui jaringan tegangan rendah kepada konsumen. Pada operasi sistem tenaga listrik sering terjadi gangguangangguan yang dapat mengakibatkan terganggunya penyaluran tenaga listrik ke konsumen. Gangguan adalah penghalang dari suatu sistem yang sedang beroperasi atau suatu keadaan dari sistem penyaluran tenaga listrik yang menyimpang dari kondisi normal. Suatu gangguan di dalam peralatan listrik didefinikan sebagai terjadinya suatu kerusakan di dalam jaringan listrik yang menyebarkan aliran arus listrik keluar dari saluran yang seharusnya. Berdasarkan ANSI/IEEE Std. 100-1992 gangguan didefinisikan sebagai suatu kondisi fisis yang disebabkan kegagalan suatu perangkat, komponen, atau suatu elemen untuk berkerja sesuai dengan fungsinya.

Sistem proteksi memegang peranan penting dalam kelangsungan dan keamanan terhadap penyaluran daya listrik. Pengamanan pada jaringan transmisi perlu mendapat perhatian yang serius dalam setiap perencanaannya. Sistem transmisi memiliki parameter-parameter dan keadaan sistem yang berubah secara terus menerus, sehingga strategi pengamanannya harus disesuaikan dengan perubahan dinamis dalam hal desain dan pengaturan peralatannya. Sistem proteksi berfungsi untuk mengamankan peralatan listrik dari kemungkinan kerusakan yang diakibatkan oleh gangguan, misalnya gangguan dari alam atau akibat rusaknya peralatan secara tiba-tiba, melokalisir daerah-daerah sistem yang mengalami gangguan sekecil mungkin, dan mengusakan secepat mungkin untuk mengatasi gangguan yang terjadi di daerah tersebut, 
sehingga stabilitas sistemnya dapat terpelihara, dan juga untuk mengamankan manusia dari bahaya yang ditimbulkan oleh listrik.

Maka, dalam hal tersebut kita harus memperhatikan pada mesin listrik. Mesin listrik itu sendiri juga masih terbagi menjadi du bagian, yaitu mesin listrik statis dan mesin listrik dinamis. Mesin listrik statis adalah transformator, alat untuk mentransfer energi listrik dari sisi primer ke sekunder dengan perubahan tegangan pada frekuensi yang sama. Mesin listrik dinamis terdiri atas motor listrik dan generator. Hal tersebut, penulis mempunyai keinginan untuk meneliti secara mendalam terkait dengan sistem proteksi pada trafo $20 \mathrm{kV}$ di gardu Induk PT. PLN (Persero) Unit Lamongan sebagai tugas akhir perkuliahan.

\section{Rumusan Masalah}

Berdasarkan uraian dalam latar belakang diatas, maka rumusan masalah yang akan dikaji adalah: (a) Bagaimana koordinasi sistem proteksi distribusi $20 \mathrm{kV}$ di PT. PLN (persero) Lamongan ?, (b) Bagaimana sistem proteksi gangguan hubung singkat pada jaringan distribusi $20 \mathrm{kV}$ ?

\section{METODE PENELITIAN \\ Teknik Analisis Data}

Teknis analisis data yang saya lakukan adalah mensurvei, analisa dan mencari refrensi serta mewawancarai berbagai sumber dari situlah maka hasil penelitian akan tampak. Analisis data mencakup seluruh kegiatan mengklasifikasikan, menganalisa, memaknai dan menarik kesimpulan dari semua data yang terkumpul. Oleh karena itu perlu menggunakan dasar pemikiran untuk menentukan pilihan-pilihan teknik analisis data yang akan digunakan.

\section{Persamaan Rumus}

Contoh perhitungan arus trafo 3 phase dengan kapasitas $200 \mathrm{kVA}$, dengan tegangan 20 $\mathrm{kV} / 400$ Volt dan tegangan hubung singkat $6 \%$.

Berapa arus nominal primer / sekunder dan arus hubung singkat bila terjadi hubung singkat di panel.

Contoh penyelesaian :

$\mathrm{P}=20 \mathrm{kVA}=200.000 \mathrm{VA}, \mathrm{V} 1=20 \mathrm{kV}=20.000$ volt, $\mathrm{V} 2=400$ volt dan $\mathrm{Z}=6 \%$

$I 1=\frac{200.000}{400 \times \mathrm{V3}}=$

5,77 Amp (Arus Nominal Primer)
$I 2=\frac{200.000}{400 \times \mathrm{V}^{3}}=$

288,7 amp (Arus Nominal Sekunder

)

$$
\begin{aligned}
& \mathrm{Z} \text { sek } \frac{\mathrm{KV}^{2}}{\mathrm{MVA}} \times \mathrm{Z}=\frac{0,4^{2}}{0,2} \times 6 \%=0,048 \mathrm{Ohm} \\
& \mathrm{I}^{\mathrm{w}}=\frac{400 / \mathrm{V}^{3}}{0,048}=
\end{aligned}
$$

4.811 Amp (Arus Hubung 3 Phase Pada Panel) atau

$$
I^{ \pm}=I 2 x \frac{100}{Z}=288.7 \times \frac{100}{6}=4.811 \mathrm{Amp}
$$

\section{Diagram Alir}

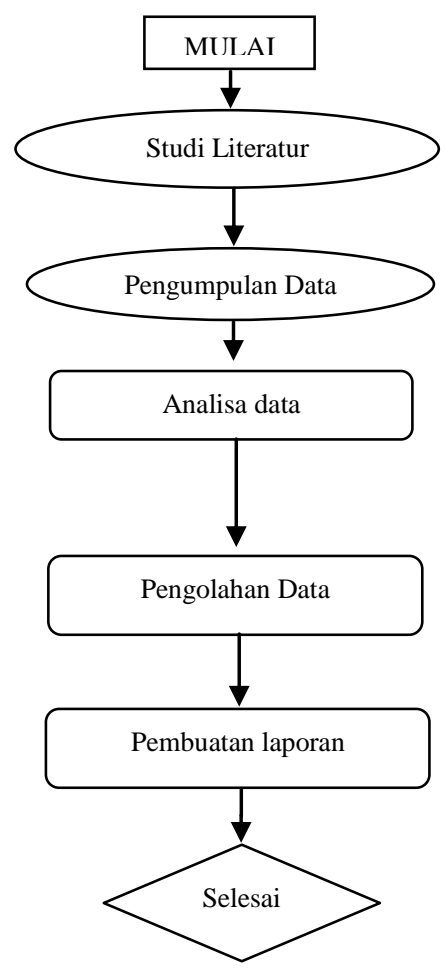

\section{Gambar 1. Diagram Alir Penelitian}

\section{HASIL DAN PEMBAHASAN \\ Profil Gardu Distribusi Lamongan}

Kemudian mencari data Single Line dari PT. PLN (Persero) Lamongan, data Single Line keseluruhan sebagai berikut : 


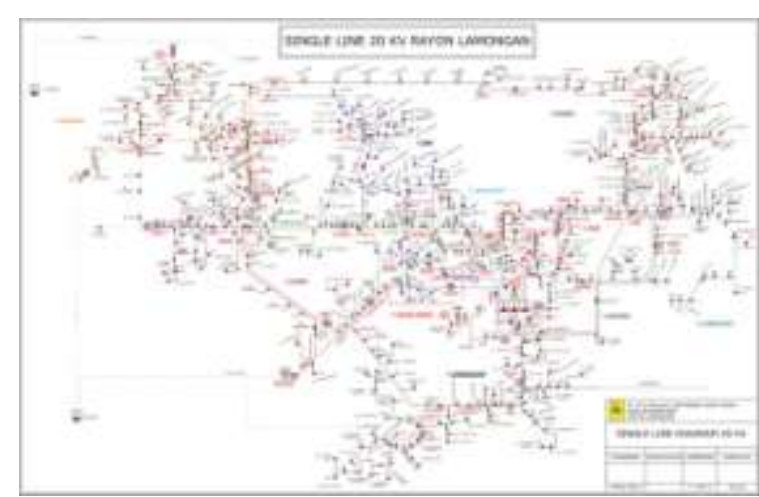

Gambar 2 Single Line Keseluruan Di PT. PLN (persero) Lamongan

\section{Deskripsi Lokasi Penelitian}

PT. PLN (Persero) Lamongan beralamat di Jalan Veteran Kecamatan Lamongan Jawa Timur, Area pelayanan PT. PLN (Persero) kota Lamongan. Adapun beberapa desa yang menjadi wilayah pelayanan Rayon Lamongan wilayah yaitu :Desa Kali Lapas, Desa Simbatan, Desa Canggah, Desa Tambak Boyo, Desa Deket Kulon , Desa Deket Wetan, Desa Rejo Sari, Desa Pandan Pancur, Desa Srirande/Sisipan, Desa Nginjen, Desa Ploso Boden, Desa Pandanan, Desa Tumapel, Desa Beru, Desa Sumber Rejo, Desa Mejuwet, Desa Sugih Waras, Desa Dinoyo, Desa Babat Agung dan Desa Rejo Tengeh

Dalam penelitian ini mengacu pada Desa Tambak Boyo. Koordinasi sistem proteksi distribusi di PT. PLN (persero) Lamongan wilayah Tambak Boyo adalah :

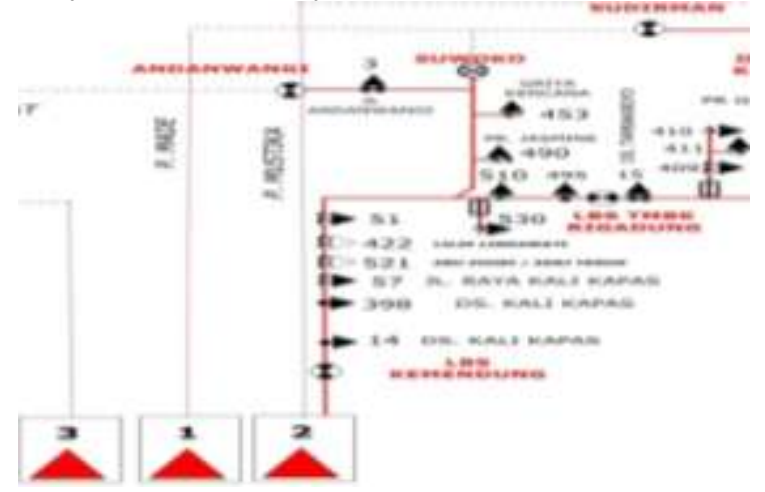

Gambar 3 Single Line Lbs Tambak Rigadung

Dalam penelitian ini gangguan pada LBS Tambak Rigadung $20 \mathrm{KV}$ dengan kapasitas Trafo 25 - $250 \mathrm{KVA}$.` Arus gangguan hubung singkat dihitung dengan menggunakan rumus HUKUM OHM yaitu :

$$
\mathrm{I}=\frac{\dot{V}}{\mathrm{Z}}
$$

dimana :
I $=$ Arus yang mengalir pada Impedansi $\mathrm{Z}$ (AMP)

$\mathrm{V}=$ Tegangan sumber $($ VOLT $)$

$\mathrm{Z} \quad=$ Impedansi jaringan yaitu nilai ekivalen dari seluruh impedansi di dalam jaringan mulai dari sumber tegangan sampai ke titik gangguan $(\mathrm{OHM})$

$$
\begin{array}{ll}
\mathrm{Xs} & =\frac{K V^{a}}{M V A} \\
\mathrm{Xs} & =\frac{20^{A}}{11.6} \\
\mathrm{Xs} & =\frac{400}{11,6} \\
\mathrm{Xs} & =34,48 \mathrm{ohm}
\end{array}
$$

Adapun penelitian di gardu distribusi Lamongan terdapat tiga jenis trafo tenaga dengan tegangan kerja 150/20 $\mathrm{kV}$ dimana masing-masing trafo berkapasitas 60 MVA. Karena pada trafo dua memasuk 5 penyulang, maka diperlukan penyetelan relay yang baik agar relay dapat memproteksi peralatan-peralatan listrik yang lain dari arus gangguan hubungan singkat maupun beban lebih. Adapun data-data yang diperlukan untuk analisis ini adalah sebagai berikut:

$$
\begin{array}{lll}
>\text { Merk } & =\text { SINTRA } \\
>\text { Daya } & =50 \mathrm{MVA} \\
> & \text { Tegangan } & =150 / 20 \mathrm{kV} \\
> & \text { Impedansi }(\mathrm{Z} \%) & =12,15 \% \\
> & \text { Teg Primer } & \multicolumn{1}{c}{=150 \mathrm{kV}} \\
> & \text { Teg Sekunder } & =20 \mathrm{kV} \\
> & \text { Ratio CT Trafo } & =2000 / 5 \\
> & \text { Arus Nominal Trafo } \quad=1443,4 \\
> & \text { Hub. Belitan Trafo }=\text { Ynyn0 }(\mathrm{d} 11) \\
> & \text { Grund Resistor }=14 \text { Ohm }
\end{array}
$$

Data hubung singkat di bus sisi primer $(150 \mathrm{kV})$ di gardu distribusi adalah sebesar 2.586 MVA. Maka impendasi sumber (Xs) adalah:

$$
s(\text { sisi } 150 \mathrm{kV})=\frac{150^{2}}{20}, h
$$

Untuk mengetahui impendasi di sisi sekunder yaitu di bus sisi $20 \mathrm{kV}$ maka:

$$
s(\text { sisi } 150 \mathrm{kV})=\frac{20^{2}}{150^{2}}, 0,155 \mathrm{~h}
$$

Besarnya reaktansi trafo tenaga satu di gardu distribusi adalah $12,13 \%$, agar dapat mengetahui besarnya nilai reaktansi urutan positif, negatif dan reaktansi urutan nol dalam ohm, maka perlu dihitung dulu besar nilai ohm pada $100 \%$ nya.

Besarnya nilai ohm pada $100 \%$ yaitu:

$$
t(\text { pada } 100 \%)=\frac{k V(\text { sisius } 2)^{2}}{\text { VA trafo }}
$$


$t($ pada $100 \%)=\frac{20^{2}}{50} h$

Nilai reaktansi trafo tenaga:

$>$ Reaktansi urutan positif, negatif $(\mathrm{Xt1}=\mathrm{Xt} 2)$ $\mathrm{Xt}=12,15 \% .8=0,972 \mathrm{Ohm}$

$>$ Reaktansi urutan nol (Xt0)

Karena trafo daya yang mensuplai penyulang mempunyai hubungan Ynyn0 yang tidak mempunyai belitan delta di dalamnya, maka besarnya Xt0 berkisar antara 9 s.d 14. Xt1, dalam perhitungan ini diambil nilai Xt0 lebih kurang 10. Xt1. Jadi $\mathrm{Xt} 0=10.0,972=9,72 \mathrm{Ohm}$.

Dari data yang diperoleh bahwa jenis penghantar yang digunakan pada penyulang hanya menggunakan satu tipe kabel yaitu XLPE $210 \mathrm{~mm} 2$.

Panjang penyulang $=5,309 \mathrm{~km}$, dengan panjang penghantar XLPE $210 \mathrm{~mm} 2=5,309 . \mathrm{Z1}$ $=\mathrm{Z} 2(\mathrm{XLPE} 210)=(0,118+\mathrm{j} 0,095) \Omega / \mathrm{km}$ $\mathrm{x} 5,309=0,624=\mathrm{j} 0,504 \mathrm{Ohm} . \mathrm{Z0}($ XLPE 210) $=$ $(0,255+\mathrm{j} 0,024) \Omega / \mathrm{km} \times 5,309=1,354=\mathrm{j} 0,127$ Ohm.

Dengan demikian nilai impendasi penyulang untuk lokasi gangguan dengan jarak $0 \%, 25 \%, 50 \%, \quad 75 \%$ dan $100 \%$ panjang penyulang, sebagaimana ditampilkan pada Tabel 4.1.

\section{Tabel 1 Impedansi Penyulang Urutan Positif dan Negatif}

(\% Impedansi Penyulang (Z1 dan Z2)

Panjang)

\begin{tabular}{|c|c|}
\hline 0 & $0 \% \cdot(0,624+\mathrm{j} 0,504)=0 \mathrm{Ohm}$ \\
\hline 25 & $\begin{array}{c}25 \% \cdot(0,624+\mathrm{j} 0,504)=0,156+ \\
\text { j0,126 Ohm }\end{array}$ \\
\hline 50 & $\begin{array}{c}50 \% \cdot(0,624+\mathrm{j} 0,504)=0,312+ \\
\mathrm{j} 0,252 \text { Ohm }\end{array}$ \\
\hline 75 & $\begin{array}{c}75 \% \cdot(0,624+\mathrm{j} 0,504)=0,468+ \\
\mathrm{j} 0,378 \text { Ohm }\end{array}$ \\
\hline 100 & $\begin{array}{c}100 \% \cdot(0,624+\mathrm{j} 0,504)=0,624+ \\
\mathrm{j} 0,504 \text { Ohm }\end{array}$ \\
\hline
\end{tabular}

Tabel 2 Impedansi Penyulang Urutan Nol

\begin{tabular}{|c|c|}
\hline $\begin{array}{c}(\% \\
\text { Panjang })\end{array}$ & Impedansi Penyulang (Z0) \\
\hline 0 & $0 \% \cdot(1,354+\mathrm{j} 0,127)=0 \mathrm{Ohm}$ \\
\hline 25 & $\begin{array}{c}25 \% \cdot(1,354+j 0,127)=0,339+ \\
\text { j0,032 Ohm }\end{array}$ \\
\hline 50 & $\begin{array}{c}50 \% \cdot(1,354+\mathrm{j} 0,127)=0,677+ \\
\mathrm{j} 0,064 \text { Ohm }\end{array}$ \\
\hline 75 & $\begin{array}{c}75 \% \cdot(1,354+\mathrm{j} 0,127)=1,016+ \\
\mathrm{j} 0,095 \mathrm{Ohm}\end{array}$ \\
\hline 100 & $\begin{array}{c}100 \% \cdot(1,354+\mathrm{j} 0,127)=1,354 \\
+\mathrm{j} 0,127 \mathrm{Ohm}\end{array}$ \\
\hline
\end{tabular}

Rumus perhitungan impedansi Ekivalen jaringan yaitu Z1eq dan Z2eq:

Z1eq dan Z2eq $=\mathrm{ZiS}($ sisi $20 \mathrm{kV})+\mathrm{ZiT}+\mathrm{Z1}$ penyulang

$=\mathrm{j} 0,155+\mathrm{j} 0,972+\mathrm{Z} 1$ penyulang

$=\mathrm{j} 1,127+\mathrm{Z} 1$ penyulang

Karena lokasi gangguan diasumsikan terjadi pada $0 \%, 25 \%, 50 \%, 75 \%$ dan $100 \%$ panjang penyulang, maka Z1eq (Z2eq) yang didapat adalah:

Tabel 3 Impedansi Ekivalen Z1eq ( Z2eq)

\begin{tabular}{cc}
\hline $\begin{array}{c}\boldsymbol{\%} \\
\text { Panjang) }\end{array}$ & $\begin{array}{c}\text { Impedansi Z1eq }( \\
\text { Z2eq })\end{array}$ \\
\hline 0 & $0+\mathrm{j} 1,127 \mathrm{Ohm}$ \\
\hline 25 & $0,156+\mathrm{j} 1,253 \mathrm{Ohm}$ \\
\hline 50 & $0,312+\mathrm{j} 1,379 \mathrm{Ohm}$ \\
\hline 75 & $0,468+\mathrm{j} 1,505 \mathrm{Ohm}$ \\
\hline 100 & $0,624+\mathrm{j} 1,631 \mathrm{Ohm}$ \\
\hline
\end{tabular}

Perhitungan Z0eq :

$$
\begin{aligned}
\text { Z0eq } & =\mathrm{Zot}+3 \mathrm{RN}+\mathrm{Z} 0 \text { penyulang } \\
& =\mathrm{j} 9,72+3 \times 14+\mathrm{Z} 0 \text { penyulang } \\
& =\mathrm{j} 9,72+42+\mathrm{Z} 0 \text { penyulang }
\end{aligned}
$$

Untuk lokasi gangguan di $0 \%, 25 \%$, $50 \%, 75 \%$ dan $100 \%$ panjang penyulang, maka perhitungan Z0eq menghasilkan:

\begin{tabular}{c|c}
\multicolumn{2}{c}{ Tabel 4 Impedansi Ekivalen Z0eq } \\
\hline $\begin{array}{c}(\% \\
\text { Panjang })\end{array}$ & Impedansi Z0eq \\
\hline 0 & $42+\mathrm{j} 9,72$ Ohm \\
\hline 25 & $42,339+\mathrm{j} 9,752$ Ohm \\
\hline 50 & $42,677+\mathrm{j} 9,784 \mathrm{Ohm}$ \\
\hline 75 & $42,016+\mathrm{j} 9,815 \mathrm{Ohm}$ \\
\hline 100 & $42,354+\mathrm{j} 9,847 \mathrm{Ohm}$ \\
\hline
\end{tabular}

Impendasi ekivalen yang telah didapatkan selanjutnya digunakan untuk menghitung arus hubung singkat menggunakan persamaan-persamaan (2), (3), (4). Hasil perhitungan disajikan pada tabel 4.5 berikut ini:

Tabel 5 Hasil Perhitungan Arus Gangguan Hubung Singkat

\begin{tabular}{|c|c|c|c|c|}
\hline \multirow{2}{*}{$(\%)$} & \multirow{2}{*}{ Jarak } & \multicolumn{3}{|c|}{ Arus Hubung Singkat (A) } \\
\cline { 3 - 5 } & & 3 fasa & 2 fasa & 1 fasa \\
\hline 0 & 0 & 10245,79 & 8873,11 & 793,18 \\
\hline 25 & 1,327 & 9215,51 & 7980,94 & 780,6 \\
\hline 50 & 2,665 & 8373,56 & 7758,34 & 768,42 \\
\hline 75 & 3,982 & 7672,64 & 6645,39 & 756,6 \\
\hline 100 & 5,309 & 7080,1 & 6132,77 & 745,15 \\
\hline
\end{tabular}


Untuk setelan relay arus lebih penyulang yang terpasang di penyulang dihitung berdasarkan arus beban maksimum. Untuk relay inverse bisa diset sebesar 1,05 sampai dengan 1,1 x Imaks, sedangkan relay definite diset sebesar 1,2 sampai dengan 1,3 x Imaks.

Persyaratan lain yang harus dipenuhi yaitu untuk penyetelan waktu minimum dari relay arus lebih (terutama dipenyulang tidak lebih kecil dari 0,3 detik). Keputusan ini diambil agar relay tidak sampai trip lagi akibat adanya arus inrush dari trafo-trafo distribusi yang sudah tersambung di jaringan distribusi, pada saat PMT penyulang tersebut dimasukan. sebagai berikut:

Untuk setelan arus beban perhitugannya

I beban $=381,26$ Ampere, $\mathrm{CT}=400 / 5 \mathrm{~A}$

I set (primer) $=1,05 \times 1$ beban

$=1,05 \times 381,26$ Ampere

Nilai arus tersebut merupakan nilai setelan pada sisi primer, sedangkan nilai yang akan disetkan pada relay adalah nilai sekundernya.oleh karena itu dihitung menggunakan nilai rasio trafo arus yang terpasang pada penyulang. Besarnya arus pada sisi sekundernya adalah :

$$
\begin{aligned}
=\frac{1}{\text { rasioCT }} \mathrm{A} & \\
& =400,32 \mathrm{x}=\frac{5}{400} \mathrm{~A} \\
& =5,004 \mathrm{~A} \\
& =5 \mathrm{~A}
\end{aligned}
$$

Perhitugan arus gangguan yang dipilih untuk menentukan besarnya setting TMS relay OCR sisi penyulang $20 \mathrm{kV}$ transformator tenaga yaitu arus gangguan hubungan singkat tiga fasa di $0 \%$ panjang penyulang. Waktu kerja paling hiller yang ditetapkan $\mathrm{t}=0.3$ detik.

Keputusan ini diambil agar relay tidak sampai trip lagi akibat adanya arus inrush dari trafo-trafo distribusi yang sudah tersambung di jaringan distribusi, pada saat PMT penyulang tersebut dimasukan. Jadi didapat :

$$
\begin{gathered}
t \frac{0,14 T s}{\left(\frac{\text { fault }}{\text { set }}\right)^{0,02}-1} \\
0,3 \frac{0,14 T s}{\left(\frac{10245,}{400,32}\right)^{0,02}-1}
\end{gathered}
$$

$$
\text { Tms }=0,144
$$

Setelan relay arus lebih incoming setelan aru nominal trafo pada sisi $20 \mathrm{kV}$ :

$$
\begin{aligned}
& \text { In }(\text { sisi } 20 \mathrm{kV}) \quad=\frac{k V A}{k V \sqrt{3}} \\
& =\frac{50000}{20 \sqrt{3}} \\
& =1443,38 \text { Ampere } \\
& =1,05.1443,38 \text { Ampere } \\
& =1515,55 \text { Ampere } \\
& \text { Iset (sekunder) } \quad=\text { Iset (primer) } \mathrm{x} \\
& \frac{1}{\text { RatioCT }} \mathrm{A} \\
& =1515,55 \times \frac{5}{2000} \mathrm{~A} \\
& =3,789 \mathrm{~A} \\
& =4 \mathrm{~A}
\end{aligned}
$$

Untuk perhiitungan setelan TMS (Time multipler Setting) Incoming sebagai berikut:

\section{T incoming}

Jadi didapat,

$$
=(0,3+0,4)=0,7 \text { detik }
$$

$$
\begin{aligned}
& T \frac{0,14 T s}{\left(\frac{f a u i t}{s e t}\right)^{0,02}}-1 \\
& T \frac{0,14 T s}{\left(\frac{10245}{1515,5 s}\right)^{0,02}-1}
\end{aligned}
$$

Tms $=0,195$

Setelan arus gangguan tanah di penyulang diset $10 \%$ arus gangguan tanah terkecil di penyulang tersebut. Hal ini dilakukan untuk menampung tahanan busur. I set (primer)

$$
\begin{aligned}
& =0,1 \times 745 \\
& =74,5 \text { Ampere } \\
& \frac{1}{\text { RatioCT }} \text { A } \\
& \begin{array}{l}
=74,5 \times \frac{5}{400} \mathrm{~A} \\
=0,93 \mathrm{~A}
\end{array}
\end{aligned}
$$$$
\text { Iset (sekunder) }=\text { Iset (primer) } \mathrm{x}
$$

Setelan TMS (Time Multipler Setting)

$$
\begin{gathered}
t \frac{0,14 T s}{\left(\frac{\text { fault }}{\text { set }}\right)^{0,02}-1} \\
0,3 \frac{0,14 T s}{\left(\frac{3,1}{4,5}\right)^{0,02}-1} \\
\text { Tms }=0,104
\end{gathered}
$$

Setelan arus relay gangguan tanah di incoming $20 \mathrm{kV}$ harus lebih sensitif, hal ini berfungsi sebagai cadangan bagi relay di penyulang $20 \mathrm{kV}$ dibuat $8 \% \mathrm{x}$ arus gangguan tanah terkecil.

$$
\begin{aligned}
\text { I set }(\text { primer) } & =0,08 \times 745 \\
& =59,6 \text { Ampere }
\end{aligned}
$$


Iset $($ sekunder $)=$ Iset $\quad$ (primer) $\mathrm{x}$ $\frac{1}{\text { RatioCT }}$ A

$$
\begin{aligned}
& =59,6 \times \frac{5}{2000} \mathrm{~A} \\
& =0,149 \mathrm{~A}
\end{aligned}
$$

Setelan TMS (Time Multipler Setting) t incoming $=(0,3=0,4)=0,7$ detik. Jadi didapatkan :

$$
\begin{gathered}
t \frac{0,14 T s}{\left(\frac{\text { fault }}{\text { set }}\right)^{0,02}-1} \\
0,3 \frac{0,14 T s}{\left(\frac{3,1}{5}\right)^{0,02}-1} \\
\text { Tms }=0,27
\end{gathered}
$$

Tabel 6 Pemeriksan Waktu Kerja Relay untuk Gangguan 2 fasa

\begin{tabular}{c|c|c|c}
\hline $\begin{array}{c}\text { Lokasi } \\
\text { Gangguan } \\
\text { panjang) }\end{array}$ & $\begin{array}{c}\text { Waktu } \\
\text { Kerja } \\
\text { Relay } \\
\text { Incoming } \\
\text { (detik) }\end{array}$ & $\begin{array}{c}\text { Waktu } \\
\text { Kerja } \\
\text { Relay } \\
\text { Penyulang } \\
\text { (detik) }\end{array}$ & $\begin{array}{c}\text { Selisih } \\
\text { Waktu } \\
\text { (detik) }\end{array}$ \\
\hline $0 \%$ & 0,759 & 0,315 & 0,444 \\
\hline $25 \%$ & 0,808 & 0,327 & 0,481 \\
\hline $50 \%$ & 0,822 & 0,33 & 0,492 \\
\hline $75 \%$ & 0,91 & 0,348 & 0,562 \\
\hline $100 \%$ & 0,963 & 0,359 & 0,604 \\
\hline
\end{tabular}

Tabel 7 Pemeriksan Waktu Kerja Relay untuk Gangguan 1 Fasa ke Tanah

\begin{tabular}{c|c|c|c}
\hline $\begin{array}{c}\text { Lokasi } \\
\text { Gangguan } \\
(\% \\
\text { panjang) }\end{array}$ & $\begin{array}{c}\text { Waktu } \\
\text { Kerja } \\
\text { Relay } \\
\text { Incoming } \\
\text { (detik) }\end{array}$ & $\begin{array}{c}\text { Waktu } \\
\text { Kerja } \\
\text { Relay } \\
\text { Penyulang } \\
\text { (detik) }\end{array}$ & $\begin{array}{c}\text { Selisih } \\
\text { Waktu } \\
\text { (detik) }\end{array}$ \\
\hline $0 \%$ & 0,711 & 0,301 & 0,410 \\
\hline $25 \%$ & 0,716 & 0,303 & 0,413 \\
\hline $50 \%$ & 0,721 & 0,305 & 0,416 \\
\hline $75 \%$ & 0,725 & 0,307 & 0,418 \\
\hline $100 \%$ & 0,729 & 0,309 & 0,420 \\
\hline
\end{tabular}

Perbandingan hasil perhitungan dengan kondisi eksisting. Tabel 8 menunjukan setting

\begin{tabular}{|c|c|c|c|}
\hline $\begin{array}{l}\mathbf{N} \\
\mathbf{0}\end{array}$ & $\begin{array}{l}\text { Nama } \\
\text { Relay }\end{array}$ & $\begin{array}{c}\text { Data hasil } \\
\text { perhitunga } \\
n\end{array}$ & $\begin{array}{l}\text { Data yang } \\
\text { Terpasang di } \\
\text { Lapangan }\end{array}$ \\
\hline 1 & $\begin{array}{c}\text { OCR } \\
\text { (sisi } \\
\text { incoming) }\end{array}$ & $\begin{array}{l}\text { TMS = } \\
0,144 \\
\text { Rasio CT }= \\
400 / 5 \mathrm{~A}= \\
\mathrm{T}=\end{array}$ & $\begin{array}{ll}\text { TMS } & =0,16 \\
\text { Rasio CT } & =2000 / 5 \\
\mathrm{~A} & \\
\mathrm{~T} & =0,7 \\
\text { detik } & \end{array}$ \\
\hline
\end{tabular}
relay arus lebih hasil perhitung dengan kondisi

\begin{tabular}{|c|c|c|c|}
\hline & & 0,3 detik & \\
\hline 2 & $\begin{array}{c}\text { GFR } \\
\text { (sisi } \\
\text { incoming) }\end{array}$ & $\begin{array}{l}\text { TMS = } \\
0,195 \\
\text { Rasio CT }= \\
2000 / 5 \mathrm{~A} \\
\mathrm{~T}= \\
0,3 \text { detik }\end{array}$ & $\begin{array}{ll}\text { TMS } & =0,26 \\
\text { Rasio CT } & =2000 / 5 \\
\mathrm{~A} & \\
\mathrm{~T} & =0,69 \\
\text { detik } & \end{array}$ \\
\hline 3 & $\begin{array}{c}\text { OCR } \\
\text { (sisi } \\
\text { penyulan } \\
\text { g) }\end{array}$ & $\begin{array}{l}\text { TMS = } \\
0,104 \\
\text { Rasio CT }= \\
400 / 5 \mathrm{~A} \\
\mathrm{~T}= \\
0,4 \text { detik }\end{array}$ & $\begin{array}{l}\text { TMS }=0,16 \\
\text { Rasio CT }=300 / 5 \\
\mathrm{~A} \\
\mathrm{~T} \\
\text { detik }\end{array}$ \\
\hline 4 & $\begin{array}{c}\text { GFR } \\
\text { (sisi } \\
\text { penyulan } \\
\text { g) }\end{array}$ & $\begin{array}{l}\text { TMS = } \\
0,27 \\
\text { Rasio CT }= \\
2000 / 5 \mathrm{~A} \\
\mathrm{~T}= \\
0,7 \text { detik }\end{array}$ & $\begin{array}{ll}\text { TMS } & =0,19 \\
\text { Rasio CT } & =2000 / 5 \\
\mathrm{~A} & \\
\mathrm{~T} & =0,29 \\
\text { detik } & \end{array}$ \\
\hline
\end{tabular}
eksisting.

Tabel 8 Perbandingan Hasil Perhitungan dengan Kondisi Eksisting
Dari Tabel 8 tentang perbandingan hasil perhitugan dengan kondisi eksisting dapat dijelaskan bahwa dari data relay OCR incoming yang telah dihitung menghasilkan $\mathrm{T}=0,3$ detik dan pada keadaan terpasang dilapangan $\mathrm{T}=0,7$ detik, pada relay GFR incoming $\mathrm{T}=0,3$ detik dan pada keadaan terpasang $\mathrm{T}=0,69$ detik. Data relay OCR penyulang yang telah dihitung menghasilkan $\mathrm{T}=0,3$ detik dan pada keadaan terpasang dilapangan $\mathrm{T}=0,7$ detik, pada relay GFR penyulang $\mathrm{T}=0,7$ detik dan pada keadaan terpasang $\mathrm{T}=0,29$ detik. Dari hasil perhitungan tersebut dapat disimpulkan bahwa waktu kinerja relay penyulang lebih lambat dibandingkan dengan waktu relay dalam perhitugan dan data dilapangan masih dalam kondisi yang sesuai (perbedaanya tidak terlalu jauh), sehingga keseluruhan setting OCR - GFR yang ada dilapagan masih dalam kondisi baik.

\section{PENUTUP}

\section{Kesimpulan}

a. Dari hasil perhitungan tersebut dapat disimpulkan bahwa waktu kinerja relay penyulang lebih lambat dibandingkan dengan waktu relay dalam perhitugan.

b. Data dilapangan masih dalam kondisi yang sesuai (perbedaanya tidak terlalu jauh), sehingga keseluruhan setting OCR - GFR yang ada dilapagan masih dalam kondisi baik.

\section{DAFTAR PUSTAKA}

Ade Wahyu Hidayat, Herri Gusmedi, Lukmanul Hakim, Dikpride Despa. 2013." Analisa Setting Rele Arus Lebih dan Rele Gangguan Tanah pada Penyulang Topan Gardu Induk 
Teluk Betung” Jurusan Teknik Elektro Fakultas Teknik Universitas Lampung.

Badaruddin, Budi Wirawan. 2014." Setting Koordinasi Over Current Relay pada Trafo 60 MVA 150/20 Kv dan Penyulang 20 KV' Program Studi Teknik Elektro, Fakultas Teknik Universitas Mercu Buana Jakarta.

Eka Setya Laksana.2007." Analisis Koordinasi Sistem Pengaman Incoming dan Penyulang Transformator 3 di GI Sukolilo Surabaya"Fakultas Teknologi Industri, Jurusan Teknik Elektro, Institut Teknologi Sepuluh Nopember Surabaya Kampus ITS Sukolilo Surabaya.

Rize Taufiq Ramadhan. 2014." Studi Koordinasi Sistem Pengaman Penyulang Trafo Iv Di Gardu Induk Waru” Kementerian Pendidikan Nasional Universitas BrawijayaFakultas Teknik Malang. 
